\title{
Entrepreneurship
}

Jan a Jun $2021-$ v.5 - n.1

ISSN: 2595-4318

This article is also available online at:

\section{Perfil do aluno da educação a distância em Porto Velho, Rondônia}

Atualmente vem ocorrendo a expansão dos cursos superiores proporcionado pelo desenvolvimento da integração da educação e das Tecnologias da Informação e Comunicação - TIC's, visando atender às exigências de profissionalização do mercado de trabalho. Contudo vem se configurando diversas preocupações no ambiente da Educação a Distância-EaD, principalmente, por exigir de professores e alunos atitudes diferenciadas: do professor exige-se a habilidade para criar condições que conduzam o aluno a aprendizagem, ao utilizar variadas ferramentas/TIC's, e entre outros; do aluno exige-se uma efetiva prática do autoestudo, da disciplina e da autonomia considerando que, este, é produtor de seu conhecimento, podendo trazer à tona suas vivências. Diante disso, o presente artigo tem como objetivo, conhecer o perfil do aluno do curso de Administração na modalidade de Educação a distância - EaD, na cidade de Porto Velho, Rondônia, enfatizando suas motivações e dificuldades no processo de aprendizagem. Para tal foi realizada uma pesquisa de natureza quanti-qualitativa, feita através de pesquisa de campo exploratória e descritiva, que busca conhecer aspectos importantes e peculiares do comportamento humano em sociedade, com aplicação virtual de questionário, por meio da ferramenta Google Docs. O resultado revelou o seguinte perfil: os acadêmicos possuem de 26 a 45 anos de idade; está atualizado com o uso da internet; trabalha na área do curso, tanto ocupando níveis de chefia como em níveis administrativos; busca flexibilidade de tempo e espaço; busca profissionalização de acordo com os critérios exigidos no mercado de trabalho; e sente dificuldade na utilização de ferramentas tecnológicas. Além disso, esses acadêmicos, são pessoas que tem conhecimento profissional, e experiências de vida que tendem a somar na construção do processo de aprendizagem Antes de iniciar o curso, os alunos tendem a acreditar que a EaD apresenta facilidades no sistema de aprovação, mas durante o curso atestam o rigor da modalidade. Assim reconhece-se que os resultados deste estudo podem orientar as ações e as práticas de Instituições e professores no modo de fazer a Educação a distância, através do esclarecimento a respeito das motivações e das dificuldades dos alunos.

Palavras-chave: Educação à distância; Curso de Administração; Perfil do aluno EaD.

\section{Distance education student profile in Porto Velho, Rondônia}

Currently, there is an expansion of higher education courses provided by the development of the integration of education and Information and Communication Technologies - ICTs, aiming to meet the demands of professionalization in the labor market. However, several concerns have been taking shape in the Distance Education-Distance Learning environment, mainly because teachers and students require different attitudes: the teacher requires the ability to create conditions that lead the student to learning, using various tools / ICTs, and among others; an effective practice of self-study, discipline and autonomy is required from the student, considering that he is a producer of his knowledge and can bring his experiences to the fore. Therefore, this article aims to get to know the profile of the student of the Administration course in distance education - Distance Education, in the city of Porto Velho, Rondônia, emphasizing their motivations and difficulties in the learning process. For this purpose, a quantitative and qualitative research was carried out, carried out through exploratory and descriptive field research, which seeks to know important and peculiar aspects of human behavior in society, with the virtual application of a questionnaire, using the Google Docs tool. The result revealed the following profile: academics are 26 to 45 years old; is updated with the use of the internet; works in the area of the course, occupying both leadership and administrative levels; seeks flexibility of time and space; seeks professionalization according to the criteria required in the job market; and finds it difficult to use technological tools. In addition, these academics are people who have professional knowledge, and life experiences that tend to add up in the construction of the learning process. Before starting the course, students tend to believe that distance education has facilities in the approval system, but during the course they attest to the rigor of the modality. Thus, it is recognized that the results of this study can guide the actions and practices of institutions and teachers in the way of doing distance education, by clarifying the motivations and difficulties of students.

Keywords: Distance education; Administration course; EaD student profile.

Topic: Educação e Treinamento Organizacional

Reviewed anonymously in the process of blind peer

Renato Lima dos Santos (D)

Faculdades Integradas Aparício Carvalho, Brasil

http://lattes.cnpq.br/2299608233875547

http://orcid.org/0000-0001-8306-3821

renato.fbr@gmail.com

Lady Day Pereira de Souza (iD

Instituto Federal de Rondônia, Brasil

http://lattes.cnpq.br/5124807480964020

http://orcid.org/0000-0003-1709-8609

ladydps@gmail.com

Marcus Vinícius Oliveira Braga

Centro Universitário São Lucas, Brasil

http://lattes.cnpq.br/1683213635601946

http://orcid.org/0000-0001-9965-8125

marcus.braga@saolucas.edu.br

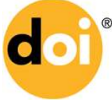

DOI: 10.6008/CBPC2595-4318.2021.001.0006
Received: 20/02/2021

Approved: 22/05/2021
Fabio Herrera Fernandes (ic)

Centro Universitário São Lucas, Brasil

http://lattes.cnpq.br/8154366932618987

http://orcid.org/0000-0003-3242-8303

fabio26012002@gmail.com

Rafael Luis da Silva (iD

Centro Universitário São Lucas, Brasil

http://lattes.cnpq.br/3368127484992279

http://orcid.org/0000-0002-9485-479X

rafaeluismat@gmail.com

\section{Referencing this:}

SANTOS, R. L.; SOUZA, L. D. P.; BRAGA, M. V. O.; FERNANDES, F. H.; SILVA, R. L.. Perfil do aluno da educação a distância em Porto Velho, Rondônia. Entrepreneurship, v.5, n.1, p.57-63, 2021. DOI: http://doi.org/10.6008/CBPC2595-4318.2021.001.0006 


\section{INTRODUÇÃO}

A Educação a distância - EaD, desde tempos idos, cumpre seu papel no sistema educacional brasileiro, oferecendo capacitação para o desenvolvimento profissional. Nesta última década, vivemos uma realidade de sua expansão no campo dos serviços educacionais, mediante a legitimação do Estado. $O$ desenvolvimento e a utilização da Tecnologia de Informação e Comunicação - TIC's, como meio de estabelecer e ofertar esta modalidade educacional, vem modificando o seu processo educativo, promovendo sua evolução em diversos níveis educacionais, principalmente no Ensino Superior.

Segundo a Associação Brasileira de Educação a Distância - ABED em seu relatório intitulado 'CensoEAD.BR', informa que em 2008 houve um crescimento de $90 \%$ do número de alunos matriculados em graduações no Brasil. Essa mesma pesquisa pontuou que dentre as áreas dos conhecimentos disponíveis, a Administração/ Gestão se configura numa das mais procuradas pelos estudantes, por se tratar de um campo profissional em crescimento. Mostrou-se ainda, uma área do saber que apresenta um tema de fácil modularização e aplicação pedagógica, possibilitando o melhor aproveitamento educacional através das ferramentas tecnológicas utilizadas na EaD.

A ampliação de mercado da EaD responde ainda ao fator social condizente com as exigências impostas pela economia da chamada 'Sociedade do Conhecimento' cujas características estão pautadas na valorização e o compartilhamento de conhecimentos, a importância da inovação do fator estratégico e o desenvolvimento de uma consciência coletiva, favorecendo aos novos arranjos de trabalhos (CORTELAZZO, 2009). Nessa perspectiva as redes sociais, econômicas e políticas são elementos que constituem as relações humanas no atual cenário, especialmente de forma interativa por meio das TIC's.

Nesta conjuntura a EaD proporciona o acesso de maior número de pessoas à educação superior, assim consideramos que suas bases pedagógicas são sustentadas nas premissas do capitalismo, que visa o lucro ao promover a educação por atacado. Porém, como Freitas (1995) elucida que em relação a educação formal "a decisão complementar, envolve assumir que entre os ambientes formais de ensino, a escola ainda é o local privilegiado, onde o ensino se dá de forma mais sistemático, desenvolvida e intencional na sociedade capitalista". Assim se considerarmos que, também, as TIC's, nos processos da EaD, se constituem neste local privilegiado por onde o conhecimento é sistematizado de forma pedagógica, que visa formar as pessoas de acordo com as exigências profissionais do mercado, percebemos a necessidade da instituição reavaliar suas práticas pedagógicas e, principalmente, conheça o perfil do aluno que escolhe se formar nesta modalidade de ensino. Este intento requer um processo de ensino e aprendizagem centrada no aluno (FERREIRA et al., 2007).

$\mathrm{Na}$ prática pedagógica da educação para adulto observa-se que em sua formação deve ser considerado o elo entre os saberes adquiridos e a situação de trabalho, em razão das imposições ligadas à transferência dos saberes adquiridos no campo social cotidiano e profissional. Neste contexto, Roegiers et al. (2004) discutem sobre os desafios que os sistemas educacionais devem superar, a saber, "a necessidade de corresponder à argumentação da quantidade e da acessibilidade das informações; a necessidade de dar 
sentido às aprendizagens; e a necessidade de eficácia interna, de eficiência e de equidade nos sistemas educacionais".

Essas necessidades são presentes nas preocupações constantes no processo da EaD, no âmbito que corresponde à relação professor/aluno e a construção de significados e sentidos na aprendizagem, articulando ainda a disposição de conteúdos e sua acessibilidade. Essas preocupações se configurando no ambiente da EaD, principalmente, por exigir de professores e alunos atitudes diferenciadas: do professor exige-se a habilidade para criar condições que conduzam o aluno a aprendizagem, ao utilizar variadas ferramentas nas / das TIC's, entre outros; do aluno exige-se uma efetiva prática do autoestudo, da disciplina e da autonomia considerando que, este, é produtor de seu conhecimento podendo trazer à tona suas vivências (KONRATH et al., 2009).

No mais, podendo ser uma forte preocupação, é o distanciamento espacial e temporal, a separação física dos alunos entre si e entre os professores, sendo esta, fortemente evidenciada. Todavia este distanciamento necessita de um controle no processo, com respostas rápidas, tanto das instituições quanto dos professores e alunos e, desta maneira, utilizando tecnologias que possam embasar melhor nos processos de ensino aprendizagem e ao mesmo tempo que proporciona liberdade ao aluno, podendo este escolher o melhor momento para o seu estudo (BÚRIGO et al., 2016)

A autonomia do aluno adulto encontra uma relação direta com as bases fundamentais da Andragogia, como explicam Gomes et al. (2006) é uma pedagogia voltada para os alunos adultos que na EaD se tornam mais adequada ao tipo de indivíduo ativo e autônomo da atual sociedade.

Neste contexto, Litto et al. (2009) indicam que o conhecimento sobre a Andragogia e seus pressupostos pode auxiliar na qualidade da Educação à distância, visando

Contribuir para a formação de um homem educado para atuação e transformação de sua realidade; contribuir para o aprimoramento do trabalhador e colaborador que garanta à organização a que pertence o capital humano e o conhecimento que a torne competitiva em termos de atuação empresarial.

Desse modo o presente estudo tem como propósito conhecer o perfil do aluno do curso de Administração na modalidade de EaD, na cidade de Porto Velho - Rondônia, enfatizando suas motivações e dificuldades no processo de aprendizagem, e entendendo que este, representa a finalidade que torna necessária a existência dos demais atores envolvidos do processo da educação a distância.

Diante disso, Schnitman (2010), afirma que "o mapeamento do perfil do aluno [...] pode contribuir para a concepção de modelos de ambientes de aprendizagem virtual, a criação de estratégias didáticopedagógicas, assim como para a criação de processos avaliativos adequados [...]". Assim reconhece-se que os resultados deste estudo podem orientar as ações e as práticas de Instituições e professores no modo de fazer a Educação a distância, através do esclarecimento a respeito das motivações e das dificuldades dos acadêmicos.

\section{MATERIAIS E MÉTODOS}

O presente estudo apresenta uma natureza quanti-qualitativa, feita através de pesquisa de campo exploratória e descritiva "que busca conhecer aspectos importantes e peculiares do comportamento humano 
em sociedade. (...) opinião de pessoas ou grupos de pessoas sobre aspectos de sua realidade" (FURASTÉ, 2006).

Gunther (2006) aponta que a pesquisa qualitativa tem como ponto de partida a valorização do caráter comunicativo da realidade social permitindo o entendimento de um fenômeno ao refazer o processo de construção dessas realidades. Baseada nesta percepção, a pesquisa buscou conhecer as dificuldades, as motivações, além de aspectos sociais, profissionais e acadêmicos dos alunos EaD, valorizando os entendimentos construídos no percussor de sua formação.

A pesquisa foi realizada no Curso Superior de Administração, de uma Faculdade de modalidade de EaD na cidade de Porto Velho, Rondônia. O modelo EaD pode ser caracterizado como semipresencial, por atuar com uma aula semanal presencial, realizada em tempo real, via satélite. Para isso utilizou-se um questionário estruturado com perguntas abertas e fechadas, que foi encaminhado para alunos graduandos em Administração, do primeiro ao oitavo período. O questionário foi elaborado e encaminhado para o e-mail dos acadêmicos por meio da ferramenta "Formulário" do Google Docs. A coleta dos e-mails foi feita no momento dos encontros presenciais, depois de esclarecido o objetivo e intuito da pesquisa. Os formulários foram devolvidos por demanda espontânea, excluindo qualquer forma de identificação.

Os questionários foram enviados e recebidos durante os meses de maio, junho e julho de 2012, sendo encaminhados para a quantidade de 129 e-mails, voltando respondidos 32 questionários.

\section{RESULTADOS E DISCUSSÃO}

Na figura 1, ficou bem evidente, que a maioria dos discentes, (62\%) são do público feminino, que em sua maioria tem dupla jornada de trabalho, conciliando seus estudos com seus afazeres domésticos (cuidar da casa e filhos), algo que ficou demonstrado também, pela pesquisa realizada pelo Instituto Brasileiro de Geografia e Estatística-IBGE, entre 2001 e 2005 (IBGE, 2007).

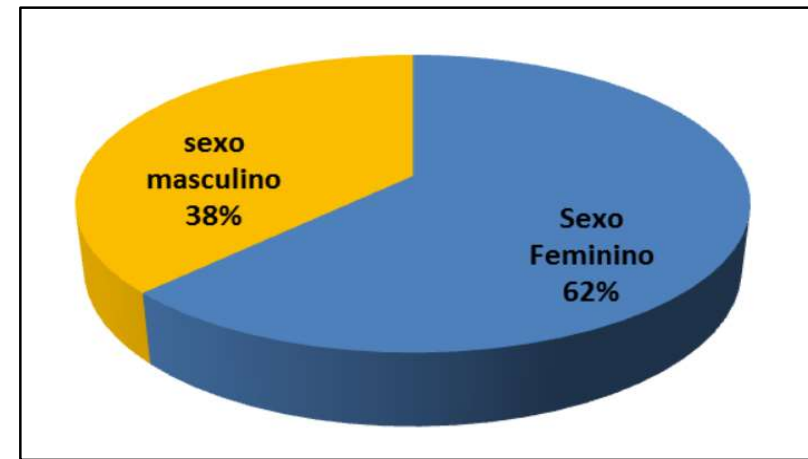

Figura 1: Relação de gênero dos acadêmicos em EaD.

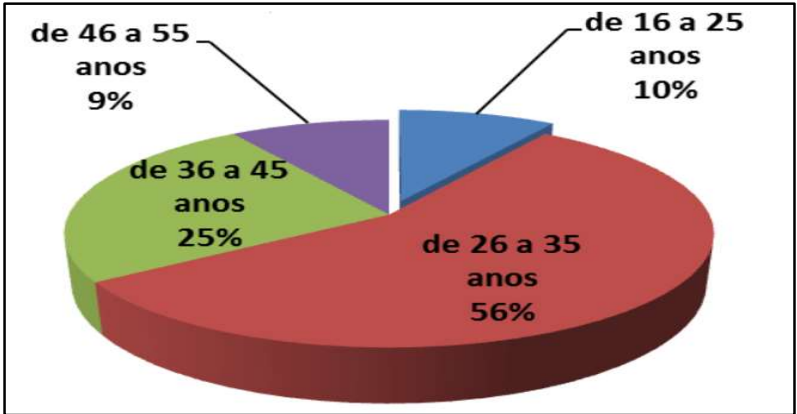

Figura 2: Faixa etária dos discentes da modalidade Ead.

Outrossim na figura 2, está devidamente em consonância com a proposta inicial da EAD, que era para atender ao público exclusivo de adultos, pois $56 \%$ dos pesquisados tem mais de 26 anos e $34 \%$ tem mais de 36 anos, que por vários motivos não conseguiram concluir seus estudos na idade desejável, no entanto precisam concluí-los para permanecer no mercado de trabalho.

Quando se faz o cruzamento das figuras 1 e 2, fica mais perceptível, a importância da EaD para os 
adultos, principalmente para as mulheres, que hoje são a maioria, nesta modalidade de ensino. Isto significa que a andragogia tem um papel importante neste avanço educacional.

Além disso, um fato bem relevante, é que $10 \%$ dos discente, estão com idade menor que 26 anos. Isso demonstra que esta modalidade pretende, inclusive colaborar com o desenvolvimento educacional e não apenas como uma alternativa de reparação de atraso social e educacional, mas também se apresenta como alternativa de realizar a primeira graduação, como verificado na figura 3.

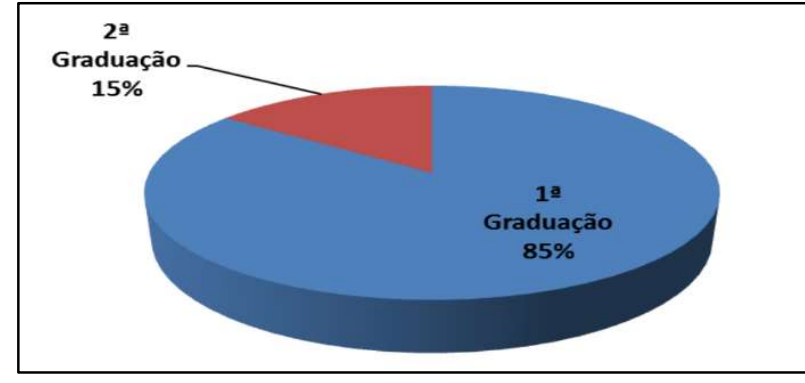

Figura 3: Quantos alunos já possuem uma graduação.

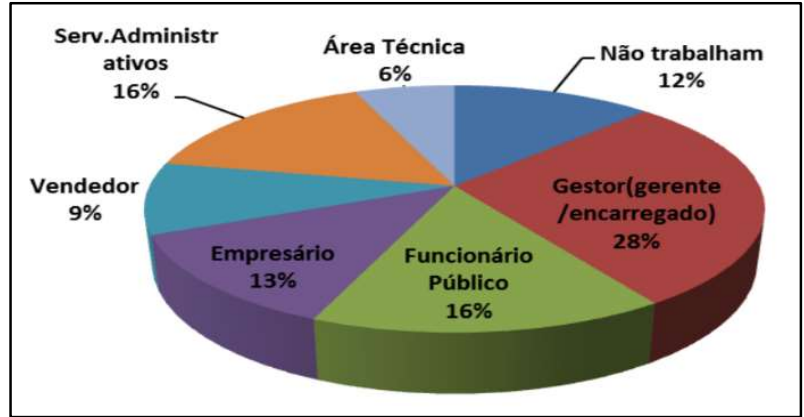

Figura 4: Quanto à ocupação de trabalho.

É possível inferir que dos 32 alunos que participaram da pesquisa, 29 buscam sua 1a graduação. Estes dados, quando comparados a figura 1, fica mais evidente a contribuição da EaD aos que não tiveram oportunidade de continuar os estudos ainda quando jovens. Os alunos buscam aprendizagem na modalidade EaD, pois atende aos seus anseios sociais, profissionais e educacionais, respeitando o que uma busca aprender para sua formação.

Em relação à ocupação, mostrada na figura 4, somente $12 \%$ não trabalham, e que $88 \%$ trabalham e encontraram na modalidade de ensino EaD uma forma de conciliar trabalho e estudo, tendo a flexibilidade para viajar a trabalho ou fazer horas extras sem comprometer seu desenvolvimento nos estudos.

Além disso, fazendo alusão a figura 5, podemos afirmar que a metodologia em EaD considera as experiências de vida e profissional como base para formar o aprendizado dos alunos, uma vez que $64 \%$ que escolheram o curso de Administração foi influenciado pelo trabalho. Segundo Litto et al. (2009) "a fonte de maior valor na educação do adulto é a experiência do aprendiz. (...) a genuína educação manterá o fazer e pensar juntos (...). A experiência é o livro vivo do aprendiz adulto". Dessa forma a aprendizagem se torna mais significativa.

Ainda de acordo com Litto et al. (2009) “(...) a análise das bases em que a andragogia leva a compreender que esse novo conceito decorre da expansão de concepções educacionais na perspectiva da formação continuada e ao longo da vida, superando o período da educação escolar".

Este conceito atribui aos números encontrados um entendimento de que a $\mathrm{EaD}$ pode atender as necessidades dos alunos, tanto com a metodologia voltada ao público adulto que visando a flexibilidade de horários, quanto a possibilidade de estudar para obter um aprendizado de qualidade e contribuir no desenvolvimento de suas carreiras nas organizações em que trabalham.

Por fim, na figura abaixo, $56 \%$ apontam a flexibilidade de tempo/horário e $22 \%$ o baixo custo, como os principais motivadores na escolha para estudar nesta modalidade. Consideramos que estes motivadores 
são facilidades proporcionadas, principalmente, pelas TICs, que permitem aos estudantes realizarem seus estudos em qualquer lugar e a qualquer horário. Conforme Oliveira (2012) as TIC's "proporcionam, progressivamente, maior flexibilidade e acessibilidade à educação, a cultura e ao desenvolvimento profissional e pessoal". Os alunos indicaram, ainda, em perguntas abertas, que escolheram a EaD por considerar a modalidade uma liberdade na aprendizagem; ou por dificuldade em ingressar na universidade pública.

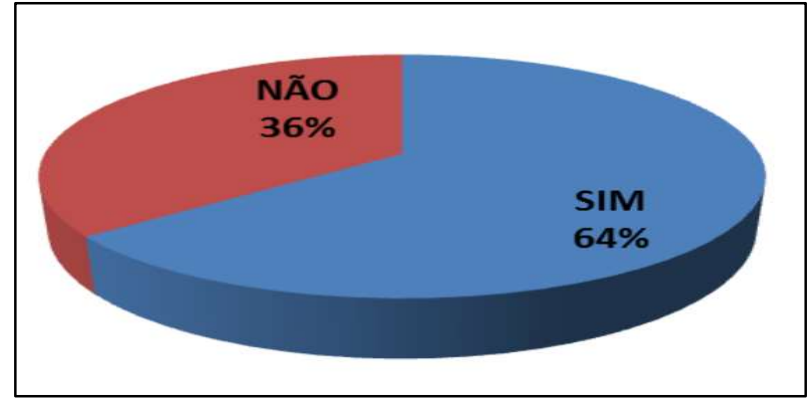

Figura 5: Influência do trabalho no curso.

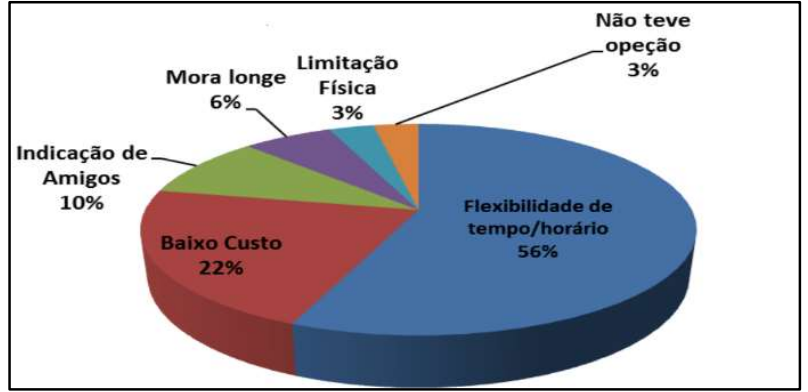

Figura 6: Escolha pela modalidade de ensino em EaD.

Inclusive, os alunos apontaram como pontos positivos: o autogerenciamento do estudo de forma a garantir melhor aprendizagem; ter material didático no Ambiente virtual; acesso a biblioteca virtual com uma bibliografia vasta e adequado ao curso; ter um tutor presencial que esclareça as principais dúvidas.

Todavia, quanto aos pontos negativos em relação a EaD, explicaram que: sentem necessidade de mais encontros presenciais; a modalidade requer disciplina para cumprir os prazos estipulados; apontaram que por não ter cobranças, acabam tendo preguiça e desânimo para continuar; muitos conteúdos não são aprofundados; citam a existência de preconceito com a modalidade por parte do mercado de trabalho e colegas.

Não se pode pensar que, por ser um ensino a distância, exista mais ou menos facilidades em obter aprovações, pois os métodos e sistemas de avaliação nesta modalidade de ensino é criteriosa tanto quanto o ensino presencial e busca formar profissionais com visão crítica e com alto nível de comprometimento e consciente de seu papel no processo de ensino aprendizado (FERNANDES et al., 2018)

Finalmente, quando questionado sobre o uso da internet no seu dia-a-dia, foi disponibilizado 4 alternativas: Leitura de noticiários, Redes Sociais, Pesquisas e, estudar e pesquisar, podendo responder mais de uma alternativa. Assim dos 32 alunos, 8 dos respondentes não incluíram o item "Estudar e Pesquisar" na utilização diária da internet. Os dados denotam que possuem alunos que não estudam pela internet, algo bem preocupante, se considerarmos que o principal ambiente de estudo na EaD é pela internet. Esta resposta pode indicar que o nosso aluno, prefere o material impresso, ou apresenta dificuldades com o manuseio digital.

\section{CONCLUSÕES}

A expansão da EaD como modalidade em instituições públicas e privadas está relacionada a muitos fatores, mas, principalmente ao desenvolvimento das TIC's, a disseminação de uma cultura originada pela 
crescente interação e construção de vivências das pessoas no espaço da internet, e pela possibilidade de aprender e construir outros conhecimentos por este meio.

O curso de Administração na modalidade de EaD tem ampliado sua oferta de vagas no mercado de Porto Velho, absorvendo uma demanda de alunos com o seguinte perfil: são pessoas adultas que estão no mercado de trabalho; apresentam dificuldades em usar algumas ferramentas tecnológicas, porém buscam flexibilidade de espaço e tempo para se qualificar. São pessoas que tem conhecimento profissional, e experiências de vida que tendem a somar na construção do processo de aprendizagem. Antes de iniciar o curso, os alunos tendem a acreditar que a EaD apresenta facilidades no sistema de aprovação, mas durante o curso atestam o rigor da modalidade.

\section{REFERÊNCIAS}

BÚRIGO, C. C. D.; CERNY, R. Z.; TEIXEIRA, G. G. S.; MARCELINO, L. V.. A gestão colaborativa no processo formativo da EaD. Revista Gestão Universitária na América Latina, v. 9, n.1, p.165-176, 2016. DOI:

http://doi.org/10.5007/1983-4535.2016v9n1p165

CORTELAZZO, I. B. C.. Prática pedagógica, aprendizagem e avaliação em EAD. Curitiba: IBPEX, 2009.

FERNANDES, E.; MANGILI, A. P. C.. A prática avaliativa na formação do sujeito no EaD nas universidades. Revista de Pós-graduação Multidisciplinar, v.1, n.5, p.139-146, 25, 2018. DOI: http://doi.org/10.22287/rpgm.v1i5.803

FREITAS, L. C.. Crítica da organização do trabalho pedagógico e da didática. Campinas: Papirus, 1995.

FERREIRA, Z. N.; MENDONÇA, G. A. A.. O perfil do aluno de educação a distância no ambiente TELEDUC. In: CONGRESSO BRASILEIRO DE EDUCAÇÃO A DISTÂNCIA, 13. Anais. Curitiba: ABED, 2007.

FURASTÉ, P. A.. Normas Técnicas para o trabalho científico: elaboração e formatação. Normas da ABNT. Porto Alegre, 2006.

GOMES, R. C. G.; PEZZI, S.; BÁRCIA, R. M.. Tecnologia e Andragogia: aliadas na educação a distância. Associação Brasileira de Educação a Distância (ABED), 2006.
GUNTHER, H.. Pesquisa Qualitativa Versus Pesquisa Quantitativa: Esta É a Questão?. Revista Psicologia: Teoria e Pesquisa. Brasília, v.22, n.2, p.201-210, 2006.

IBGE. Instituto Brasileiro de Geografia e Estatística. Tempo, Trabalho e afazeres domésticos: um estudo com base nos dados da pesquisa nacional por amostra de domicilio de 2001 a 2005. IBGE, 2007.

KONRATH, M. L. P.; TAROUCO, L. M. R.; BEHAR, P. A.. Competências: desafios para alunos, tutores e professores de EAD. Renote: Novas Tecnologias na educação, Rio Grande do Sul, v.7, n.1, 2009.

LITTO, F. M.; FORMIGA, M. M. M.. Educação a distância: o estado da arte. São Paulo: Pearson, 2009.

OLIVEIRA, E. G.. Educação à distância na transição paradigmática. 4 ed. Campinas: Papirus, 2012.

ROEGIERS, X.; DE KETELE, J. M.. Uma pedagogia da integração: competências e aquisições no ensino. Porto Alegre: Artmed, 2004

SCHNITMAN, I. M.. O perfil do aluno virtual e as teorias de estilos de aprendizagem. In: SIMPÓSIO HIPERTEXTO E TECNOLOGIAS NA EDUCAÇÃO, 3. Anais. Recife: UFPE, 2010.

A CBPC - Companhia Brasileira de Produção Científica (CNPJ: 11.221.422/0001-03) detém os direitos materiais desta publicação. Os direitos referem-se à publicação do trabalho em qualquer parte do mundo, incluindo os direitos às renovações, expansões e disseminações da contribuição, bem como outros direitos subsidiários. Todos os trabalhos publicados eletronicamente poderão posteriormente ser publicados em coletâneas impressas sob coordenação da Sustenere Publishing, da Companhia Brasileira de Produção Científica e seus parceiros autorizados. Os (as) autores (as) preservam os direitos autorais, mas não têm permissão para a publicação da contribuição em outro meio, impresso ou digital, em português ou em tradução. 